\title{
EG Cell Line
}

National Cancer Institute

\section{Source}

National Cancer Institute. EG Cell Line. NCI Thesaurus. Code C20231.

Human EG cells are derived from the primordial germ cells, which occurs in a specific part

of the embryo/fetus called the gonadal ridge, and which normally develop into mature gametes (eggs and sperm). Growing pluripotent cells derived from EG cells requires the generation of embryoid bodies, which consist of an unpredictable mix of partially differentially cell types. 